\title{
Daylight photodynamic therapy - Experience and safety in treatment of actinic keratoses of the face and scalp in low latitude and high brightness region*
}

\author{
Luiz Eduardo Garcia Galvão ${ }^{1}$ \\ Karine Paschoal Botelho ${ }^{1}$
}

\author{
Heitor de Sá Gonçalves ${ }^{1}$ \\ Juliana Chagas Caldas ${ }^{1}$
}

DOI: http:/ / dx.doi.org/10.1590/abd1806-4841.20175175

\begin{abstract}
Daylight photodynamic therapy has been used in countries with high latitudes during the summer for actinic keratoses treatment with reports of similar efficacy to conventional photodynamic therapy. We evaluate its safety in 20 patients in the city of Fortaleza, a local with low latitude and high brightness. Sixteen patients did not report any discomfort due to the procedure. Daylight photodynamic therapy is an easy application method with great tolerability by the patient and has the possibility of being performed throughout the year in these regions. It can mean a promising tool in the control of skin cancer. Keywords: Keratosis, actinic; Skin neoplasms; Sunlight
\end{abstract}

Photodynamic therapy (PDT) is a therapeutic method for actinic keratoses (AK), the most common premalignant skin lesion. In some patients, AK multiple lesions are observed and the concept of field cancerization is applied: a region containing subclinical and multifocal pre-neoplastic abnormalities with genetic mutations that may be the site of new primary tumors and local recurrence. ${ }^{1}$

In patients with low phototype and field cancerization, PDT addresses not only clinically visible "target lesions" but also the subclinical ones that go unnoticed at the dermatological examination. ${ }^{2}$

In the conventional PDT, a photosensitizer (aminolevulinate - ALA - and methylaminolevulinate - MAL) is activated by a light of adequate length, producing a metabolite called protoporphyrin IX (PpIX), which, in contact with intracellular oxygen, selectively penetrates pre-neoplastic cells causing necrosis and apoptosis. ${ }^{3}$ After MAL application to a cutaneous field cancerization with AK, occlusion with plastic film and aluminum foil is required to avoid the early activation of PpIX by visible light. The first study that observed daylight effectiveness for PpIX activation was conducted by Wiegell et al. in 2008, in which, after 30 minutes of MAL cream's occlusion on AK of face and scalp, patients were exposed to daylight for 2 hours and 30 minutes, with similar efficacy to conventional
PDT, but with higher tolerance to the procedure and less erythema. ${ }^{4}$ European and Australian multicentric studies have confirmed the same findings. ${ }^{5}$ The city of Fortaleza is located in the state of Ceará at a low latitude $\left(03^{\circ} 43^{\prime} 02^{\prime \prime} \mathrm{S}\right)$ compared with cities where the main studies of daylight PDT were performed (between $20^{\circ}$ and $40^{\circ}$ in Australia and between $40^{\circ}$ and $60^{\circ}$ in Europe.) Our study evaluates the tolerability of this method in a region of low latitude, characterized by intense luminosity and incidence of ultraviolet rays, when compared with cooler localities with fewer sunny days.

Twenty patients were selected, with phototypes from I to IV, including 3 albino patients, with face and scalp AK. A SPF50 sunscreen was applied, without titanium dioxide or zinc oxide, to not reflect the luminosity and to allow the activation of PpIX. After 15 minutes, the curettage of rougher AK was conducted to remove scales, avoiding bleeding. Then, a thin layer of MAL cream on the face and/ or scalp was applied. Patients were observed for 30 minutes and after that, they had to remain outdoors for 2 hours, between 8 and 10 a.m., with a minimum of 10 minutes, in direct exposure to the sun in the area to be treated. Then, they returned for the removal of the product, after which the erythema was observed and they were asked about pain sensitivity during this period.

Received on 13.08.2015

Approved by the Advisory Board and accepted for publication on 02.12.2015

Work conducted at Centro de Dermatologia Dona Libânia - Fortaleza-CE, Brazil

Financial Support: None.

Conflict of Interest: None.

Service of Dermatology of the Centro de Dermatologia Dona Libânia - Fortaleza (CE), Brazil.

C2017 by Anais Brasileiros de Dermatologia 


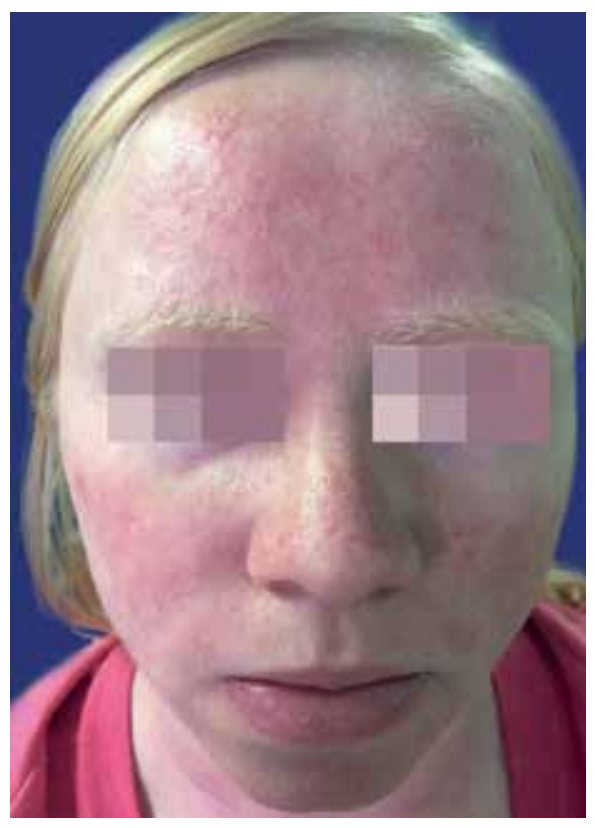

FIGURE 1:

Moderate erythema in albino patient in immediate post-procedure
When released, patients were recommended strict photoprotection. Patients were photographed before and after the procedure. Only one patient, albino, presented moderate erythema on face after 2 hours of outdoor exposure, showing no alterations in other photoexposed areas, using sunscreen and without photosensitizing medication (Figure 1). Three patients had a 2-hour exposure that was impaired by cloudy weather, rain or insufficient exposure, whereas 16 patients did not observe any discomfort, with discrete erythema in previously healed areas (Figure 2). The concern in countries with temperate climate is the possibility of not occurring the activation of PpIX in places with few sunny days in the year. ${ }^{6}$ Fortaleza is characterized by sunny days most time of the year, not having the limitation of low luminosity to use this PDT method. However, due to the vertical incidence of ultraviolet rays at low latitudes associated with intense light, a low tolerance could be observed for the exposure of 2 hours of MAL cream on face and scalp. In this study, most patients $(80 \%$ or $16 / 20)$ reported minimal discomfort during the stay in a shaded open area, and the only patient who presented a more intense erythema was albino. The remaining three patients were not assessed for operational problems reported.

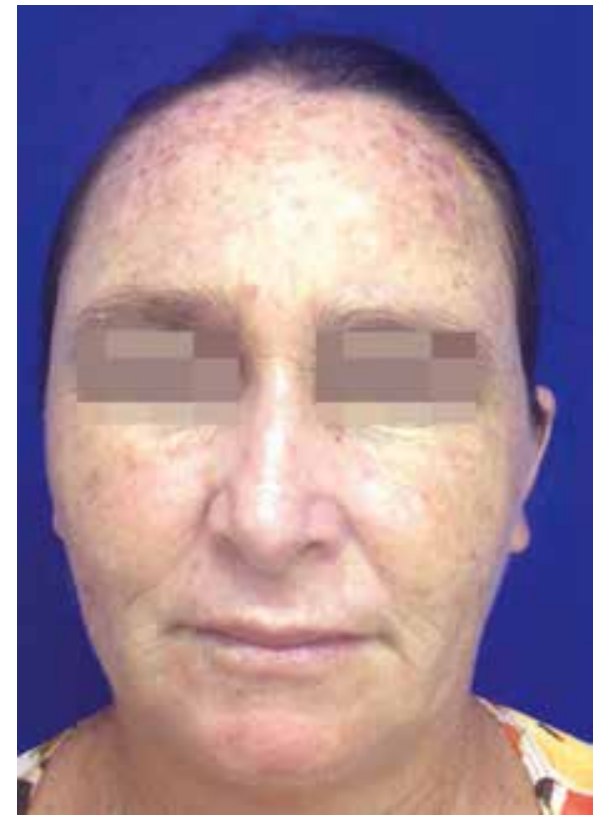

FigURE 2:

Absence of edema or significant erythema in the immediate post-procedure
This study demonstrates the tolerability and safety of a simple, inexpensive and operational method, reinforcing its importance as a gold standard for the treatment of face and scalp AK in those patients with field cancerization that have already performed other treatments limited to target lesions, such as liquid nitrogen cryotherapy. ${ }^{7}$ PDT also differs from imiquimod and 5-fluorouracil because of its greater tolerance, since erythema of PDT lasts at most a few days in contrast to the prolonged irritation caused by these other treatments. ${ }^{8,9}$ Daylight PDT is an emergent modality in the treatment of the field cancerization by several aspects: it does not require the manufacture of a mask with plastic film and aluminum foil; it offers greater practicality and easy application; it has a lower cost and possibility of realization by a greater number of professionals for the non-dependence of LED; it confers a greater tolerance on the part of the patient, since it does not present significant erythema or pain sensitivity; it can be used in regions with low latitude near the line of Ecuador almost every day of the year, with similar results to European and Australian high-latitude centres. ${ }^{10}$ Finally, considering all the aspects mentioned, our results reinforce the possibility of using daylight PDT as an important tool for the control of skin cancer at Public Health level.] 


\section{REFERENCES}

1. Braakhuis BJ, Tabor MP, Kummer JA, Leemans CR, Brakenhoff RH. A Genetic Explanation of Slaughter's Concept of Field Cancerization: Evidence and Clinical Explications. Cancer Res. 2003;63:1727-30.

2. Torezan LA, Festa-Neto C.Cutaneous Field Cancerization: clinical,histopathological and therapeutic aspects. An Bras Dermatol. 2013;88:775-86.

3. Braathen LR, Szeimies RM, Basset-Seguin N, Bissonnette R, Foley P, Pariser D, et al. Guidelines on the use of photodynamic therapy for nonmelanoma skin cancer: an international consensus. International Society for Photodynamic Therapy in Dermatology, 2005. J Am Acad Dermatol. 2007;56:125-43.

4. Wiegell SR, Haedersdal M, Philipsen PA, Eriksen P, Enk CD, Wulf HC. Continuous activation of PpIX by daylight is as effective as and less painful than conventional photodynamic therapy for actinic keratoses; a randomized, controlled, singleblinded study. Br J Dermatol. 2008;158:740-6.

5. Rubel DM, Spelman L, Murrell DF, See JA, Hewitt D, Foley P, et al. Daylight photodynamic therapy with methyl aminolevulinate cream as a convenient, similarly effective, nearly painless alternative to conventional photodynamic therapy in actinic keratosis treatment: a randomized controlled trial. $\mathrm{Br} \mathrm{J}$ Dermatol. 2014;171:1164-71

6. Wiegell SR, Wulf HC, Szeimies RM, Basset-Seguin N, Bissonnette R, Gerritsen $\mathrm{MJ}$, et al. Daylight Photodynamic therapy for actinic keratosis:an international consensus: International Society for Photodynamic Therapy in Dermatology. J Eur Acad Dermatol Venereol. 2012;26:673-9.

7. Freeman M, Vinciullo C, Francis D, Spelman L, Nguyen R, Fergin P, et al. A comparison of photodynamic therapy using topical methyl aminolevulinate(metvix) with single cycle cryotherapy in patients with actinic keratosis: a prospective, randomized study. J Dermatolog Treat. 2003;14:99-106.

8. Webber A, Bakos L, Kuhl ICP, Meotti CD, Muller LFB. Photodynamic Therapy versus imiquimod in the treatment of multiple actinic keratoses of the face: a comparative randomized study. Surg Cosmet Dermatol. 2014;6:325 $\neg-9$.

9. Yentzer B, Hick J, Williams L, Inabinet R, Wilson R, Camacho FT, et al. Adherence to a topical regiment of 5 -fluorouracil, $0.5 \%$, cream for the treatment of actinic keratoses. Arch Dermatol. 2009;145:203-5.

10. Grinblat BM, Festa Neto C, Sanches JA Jr, Szeimies RM, Oliveira AP, Torezan LA. Daylight photodynamic therapy for actinic keratoses in São Paulo, Brazil. Photodermatol Photoimmunol Photomed. 2015;31:54-6.
MAILING ADDRESS:

Karine Paschoal Botelho

R. Dom Pedro I, 1033

Centro

60035-100 - Fortaleza - CE

Brazil

Email: kpaschoalbotelho@yahoo.com.br

How to cite this article: Galvão LEG, Gonçalves HS, Botelho KP, Caldas JC. Daylight photodynamic therapy Experience and safety in treatment of actinic keratoses of the face and scalp in low latitude and high brightness region. An Bras Dermatol. 2017;92(1):142-4. 